\title{
Doxorubicin Contamination on the External Surfaces of Drug Vials
}

\author{
Akihiro Takeda*1, Hiroyuki Nakano², Yukio Kadokawa², Takashi Kimura², Akiko Asada', \\ Takaomi Tagami ${ }^{1}$, Takahiro Doi ${ }^{1}$, Keiji Kajimura ${ }^{1}$ and Yoshiyuki Sawabe ${ }^{1}$ \\ Department of Environmental Health, Osaka Prefectural Institute of Public Health ${ }^{1}$, \\ Department of Pharmacy, Osaka Medical Center for Cancer and Cardiovascular Diseases ${ }^{2}$ \\ $\left[\begin{array}{l}\text { Received October 12, } 2012 \\ \text { Accepted October 9, } 2013\end{array}\right]$
}

Contamination of the external surfaces of drug vials with antineoplastic drugs has been reported in some countries. However, this has rarely been reported in Japan. The aim of this study was to investigate the external contamination level of doxorubicin vials in Japan. The external surfaces of 57 vials of six products containing doxorubicin were wiped with a non-woven fabric, and the contamination levels of doxorubicin were analysed by high-performance liquid chromatography combined with fluorescence detection; doxorubicin was confirmed by high performance liquid chromatography combined with quadrupole time-of-flight mass spectrometry. The surfaces of 28 of 57 vials were contaminated with doxorubicin. The maximum contamination level was $12.3 \mathrm{ng}$ per vial. The external surfaces of some doxorubicin product vials produced by Japanese pharmaceutical companies were contaminated with doxorubicin.

Key words — doxorubicin, antineoplastic drug, external contamination, drug vial

\section{Introduction}

Although antineoplastic drugs are prescribed to treat cancer, they are themselves mutagenic, teratogenic and carcinogenic. In fact, many are classified as either Group 1, carcinogenic to humans, or Group 2, probably or possibly carcinogenic to humans, by the International Agency for Research on Cancer (IARC) of the World Health Organization (WHO), (Agents Classified by the IARC Monographs, Volumes 1-104, URL: http://mono graphs.iarc.fr/ENG/Classification/index.php).

In general, antineoplastic drugs are administered by transfusion; therefore, medical staff is exposed through drug preparation, administration and disposal. In fact, it has been reported since 1970s that occupational exposures to antineoplastic drugs may affect the health of medical staff.
Falck et al detected higher mutagen levels in the urine of nurses who prepared and administered antineoplastic drugs than in those who did not. ${ }^{1)}$ Thus, the National Institute for Occupational Safety and Health (NIOSH) in the United States published an alert concerning occupational exposures to hazardous drugs, including antineoplastic drugs, in 2004 (NIOSH Alert: Preventing Occupational Exposures to Antineoplastic and Other Hazardous Drugs in Health Care Settings, DHHS (NIOSH) (2004) Publication Number 2004-165, URL: http://www.cdc.gov/niosh/docs/2004-165/ pdfs/2004-165.pdf).

Furthermore, several studies have found that the external surfaces of new drug vials were contaminated with antineoplastic drugs. ${ }^{2-7)}$ However, the similar contamination has also been reported in Japan. ${ }^{8-9)}$ In addition, contamination levels dif-

\footnotetext{
* 3-69, 1-chome, Nakamichi, Higashinari-ku, Osaka 537-0025, Japan
} 
fer among countries or pharmaceutical industries. Thus, it is necessary to understand the actual state of contamination on the surfaces of drug vials in Japan.

While doxorubicin (DXR) has been used to treat many cancers because of its broad antitumor spectrum as monotherapy and multidrug therapy, it is one of the most likely sources of occupational exposures.

We investigated the contamination level on the external surfaces of DXR vials in Japan to acquire more knowledge about the external contamination of vials in Japan. In this paper, we report the external contamination level of DXR vials on account of the detection for the first time in Japan contrary to the past report.

\section{Materials and Methods}

\section{Pharmaceutical products}

We investigated six parenteral injection products containing 10 or $50 \mathrm{mg}$ DXR hydrochloride (DXR $\mathrm{HCl}$ ) that were commercially available in Japan. The $50 \mathrm{mg}$ DXR vials were larger than the $10 \mathrm{mg}$ vials. The $50 \mathrm{mg}$ DXR vials were packaged in cardboard boxes individually, whereas the $10 \mathrm{mg}$ DXR vials were packaged as 10 vials in one cardboard box. The same lot of each product was used in the study. In addition, none of the vials were covered with additional materials such as plastic.

\section{Chemicals}

DXR HCl (biochemistry grade), 2-propanol (HPLC grade), dichloromethane (HPLC grade), methanol (LC/MS grade), acetonitrile (LC/MS grade) and formic acid (LC/MS grade) were obtained from Wako Pure Chemical Industries, Ltd (Osaka, Japan).

Fluorescein sodium salt was obtained from
Sigma-Aldrich Japan Co LLC (Tokyo, Japan).

\section{Wipe sampling of drug vials}

We wiped the external surface of drug vials with quarter non-woven fabric (one-shot dry, 4 $\mathrm{cm} \times 4 \mathrm{~cm}$, Hakujuji Co, Ltd, Tokyo, Japan) wetted with $200 \mu \mathrm{L}$ of 2-propanol. When wiping, we held the neck of a drug vial with a pair of tweezers and used another pair of tweezers to wipe the side and bottom of the drug vial with the non-woven fabric. Then the non-woven fabric was placed into a $15-\mathrm{mL}$ polypropylene tube, and stored at $4{ }^{\circ} \mathrm{C}$ until analysis.

\section{Preparation of the sample solutions for HPLC}

The sample solutions were prepared from the non-woven fabric, as described previously. ${ }^{8)}$ In brief, the non-woven fabric was shaken with 3 $\mathrm{mL}$ of 2-propanol/ dichloromethane (60:40) in a $15-\mathrm{mL}$ polypropylene tube and sonicated for 30 min. A 2-mL aliquot of the extract was collected into a glass tube, and $25 \mu \mathrm{L}$ of $40 \mathrm{ng} / \mathrm{mL}$ fluorescein sodium salt in $10 \%$ methanol solution was added. Then, a vacuum concentration centrifuge was used to evaporate the extract. The residue was dissolved in $120 \mu \mathrm{L}$ of mobile phase (see below) and filtered through Millex ${ }^{\circledR}$-LH $(0.45 \mu \mathrm{m}, 4-\mathrm{mm}$ id; Merck-Millipore Co, Bedford, MA, USA).

\section{HPLC-Fluorescence analysis}

A Waters Alliance e2695 separation module equipped with the Waters 2475 Multi-Wavelength Fluorescence (FL) Detector (Waters) was used for HPLC-FL analysis. The HPLC separations were performed at $40{ }^{\circ} \mathrm{C}$ on a TSKgel ${ }^{\oplus}$ ODS-80Ts HPLC column $(150 \mathrm{~mm} \times 4.6-\mathrm{mm}$ id, $5-\mu \mathrm{m}$ particle size; TOSOH CORPORATION, Tokyo, Japan) under isocratic conditions. The mobile 
phase consisted of $20 \mathrm{mM}$ phosphate buffer $(\mathrm{pH}$ 5.5) and acetonitrile in the ratio 65:35, and the flow rate was $1.0 \mathrm{~mL} / \mathrm{min}$. The volume of the injected sample was $20 \mu \mathrm{L}$. The excitation and emission wavelengths were 470 and $550 \mathrm{~nm}$, respectively. The results of external contamination analysis were calculated by Microsoft ${ }^{\circledast}$ Co Excel 2010 (version 14.0 Redmond, WA, USA).

\section{LC-time-of-flight (TOF) MS analysis}

An Agilent 1290 Infinity Series HPLC system was coupled with an Agilent 6530 Accurate Mass Q-TOF LC/MS System equipped with an electrospray ionization (ESI) source (LC-TOF MS). Aliquots $(3 \mu \mathrm{L})$ of a sample were injected onto ZORBAX Eclipse Plus C18 column (100 mm $\times$ 2.1-mm id, 1.8- $\mu \mathrm{m}$ particle size, Agilent Technologies Inc, Palo Alto, CA, USA) with a mobile phase flow rate of $0.2 \mathrm{~mL} / \mathrm{min}$. The mobile phase was $0.1 \%$ formic acid in water $/ 0.1 \%$ formic acid in acetonitrile (75:25). The column oven was operated at $40{ }^{\circ} \mathrm{C}$. The ESI source was operated in positive mode, and the following instrumental parameters were used: sheath gas temperature: $300{ }^{\circ} \mathrm{C}$; sheath gas flow: $7 \mathrm{~L} / \mathrm{min}$; nebulizer: 50 psi; dry gas temperature: $350{ }^{\circ} \mathrm{C}$; dry gas flow: 10 $\mathrm{L} / \mathrm{min}$; and capillary entrance voltage: $3000 \mathrm{~V}$. The MS scan data were collected in the range of $m / z, 100-1000$.

MassHunter Data Acquisition B.02.00 software (Agilent) was used to collect the MS data, and MassHunter Qualitative Analysis B.02.00 software (Agilent) was used to identify DXR.

\section{Results}

\section{Evaluation of analysis for DXR}

Retention times of DXR and fluorescein (inter-

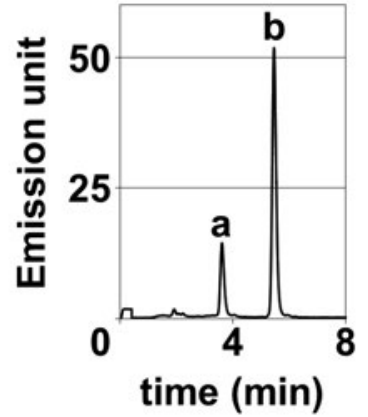

Fig. 1 Detection of the external contamination on a DXR vial with HPLC-FL

The chromatogram was obtained from the wipe sample containing the maximum amount of DXR (12.3 ng/vial). (a) doxorubicin, (b) fluorescein $(25 \mathrm{ng} / \mathrm{mL})$

nal standard) were 3.6 and 5.4 minutes, respectively (Fig. 1). We first estimated analysis for DXR within $0.8-833.3 \mathrm{ng} / \mathrm{mL}$ (the range is equivalent to the external contamination level $0.15-150$ ng per a vial of DXR). The limit of quantitation was $5.8 \mathrm{ng} / \mathrm{mL}$, that signal to noise ratio was above 10 for reference "Validation of Analytical Procedures: Methodology: Text and Methodology" (URL: http://www.ich.org/products/guidelines/ quality/quality-single/article/validation-of-analyt ical-procedures-text-and-methodology.html). And, the peak area versus concentration of DXR was plotted within $5.8-833.3 \mathrm{ng} / \mathrm{mL}$. Slope, intercept and correlation coefficient were 0.041, -0.059 , and 0.998 , respectively.

\section{Evaluation of wiping of the external surfaces of drug vials}

Before analysing external contamination level of vials, we performed wiping test for this study. We dropped DXR solution (2-propanol) on glass plates and dried it within a radius of $5 \mathrm{~cm}$ to add $5 \mathrm{ng}$ and $10 \mathrm{ng}$ DXR on the glass plates $(\mathrm{n}=3)$. Then, we wiped the divisions on the glass plates, and evaluated recovery of DXR.

Ninety four percent and $83 \%$ of $5 \mathrm{ng}$ and $10 \mathrm{ng}$ 
DXR, respectively, were recovered from the glass plates, and the relative standard deviation were 0.13 and 0.12 , respectively.

\section{Contamination level on the external surfaces of drug vials}

We analyzed 57 vials of six products containing 10 or $50 \mathrm{mg}$ of the material from three Japanese pharmaceutical companies by HPLC-FL and found 28 vials that were contaminated with DXR (Fig. 1, Table 1). Before wipe sampling, the cardboard boxes and outer sides of drug vials were visually inspected to detect contamination by breakage or leakage; no sign of damage was detected.

We compared the surface contamination on two vials sizes from the same company. The $10 \mathrm{mg}$ vials were highly contaminated as compared with $50 \mathrm{mg}$ vials. We also wiped the surfaces of vials containing another lot of Product No. 5. The results from the two lots of Product No. 5 are presented in Table 2, which revealed that the contamination levels were different between the lots even though the manufacturing process was same.

\section{Confirmation of DXR with LC-TOF MS}

The wipe sample containing the maximum amount of DXR was identified DXR by LC-TOF MS. The theoretical $\mathrm{m} / \mathrm{z}$ of $[\mathrm{M}+\mathrm{H}]^{+}$ion of DXR is 544.1813. We obtained an extracted ion chromatogram (EIC) with the $m / z 544.18$ for standard DXR preparation $(1 \mathrm{ppm})$ and the wipe sample. The retention times of the sample and the standard corresponded at approximately 4 min (Fig. 2A). The $m / z$ of $[\mathrm{M}+\mathrm{H}]^{+}$ion of the DXR standard preparation was the same as the theoretical $\mathrm{m} / \mathrm{z}$ of DXR (544.1813), and $m / z$ of the wipe sample was 544.1809 , with an error of $-0.74 \mathrm{ppm}$.

Furthermore, fragmentation of the DXR ion has been shown to produce prominent fragments of $m / z$ 397.0931. ${ }^{10)}$ We also observed a peak at $m / z$ 397.09 in EICs of the DXR standard preparation and the wipe sample. As expected, the retention times were the same (Fig. 2B).

Because the accurate mass, retention time and fragment ion of the wipe sample corresponded with those of the DXR standard preparation, the contaminant in the wipe samples was confirmed to be DXR.

Table 1 Quantitative results of the external contamination of doxorubicin

\begin{tabular}{|c|c|c|c|c|c|c|c|}
\hline Product & Companies & $\begin{array}{l}\text { Contents } \\
(\mathrm{mg})\end{array}$ & Number of Vials & $\begin{array}{c}\text { Number of } \\
\text { contaminated vials }\end{array}$ & $\begin{array}{c}\text { Contamination level } \\
\text { (ng/vial) }\end{array}$ & $\begin{array}{l}\text { Meana) } \\
\text { (ng/vial) }\end{array}$ & $\mathrm{SD}^{\mathrm{b})}$ \\
\hline 1 & A & 10 & 10 & 1 & $N^{c)}-2.32$ & 2.32 & - \\
\hline 2 & A & 50 & 10 & 10 & $2.62-4.76$ & 3.69 & 0.67 \\
\hline 3 & $\mathrm{~B}$ & 10 & 10 & 4 & ND-6.71 & 4.16 & 1.76 \\
\hline 4 & $\mathrm{~B}$ & 50 & 10 & 4 & ND-3.42 & 2.78 & 0.46 \\
\hline 5 & $\mathrm{C}$ & 10 & 10 & 9 & ND-12.3 & 4.76 & 3.11 \\
\hline 6 & $\mathrm{C}$ & 50 & 7 & 0 & ND & ND & - \\
\hline
\end{tabular}

a) Only quantitated contamination levels were used to calculate the means. b) Standard deviation. ${ }^{\text {c) }}$ Not detected.

Table 2 Comparison of the surface contamination level between different lots of the same product

\begin{tabular}{ccccccc}
\hline \hline Lot & $\begin{array}{c}\text { Term of } \\
\text { validity }\end{array}$ & Number of vials & $\begin{array}{c}\text { Number of } \\
\text { contaminated vials }\end{array}$ & $\begin{array}{c}\text { Contamination level } \\
(\text { ng/vial })\end{array}$ & Mean $^{\text {a })}$ & SL $^{\text {b) }}$ \\
\hline 1 & $12 / 2013$ & 10 & 9 & $\mathrm{ND}^{\mathrm{c}}-12.3$ & 4.76 & 3.11 \\
2 & $08 / 2013$ & 10 & 3 & ND-2.65 & 2.53 & 0.15 \\
\hline
\end{tabular}

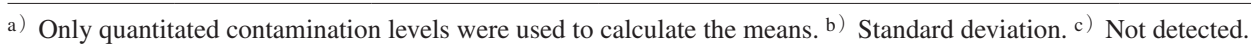


A

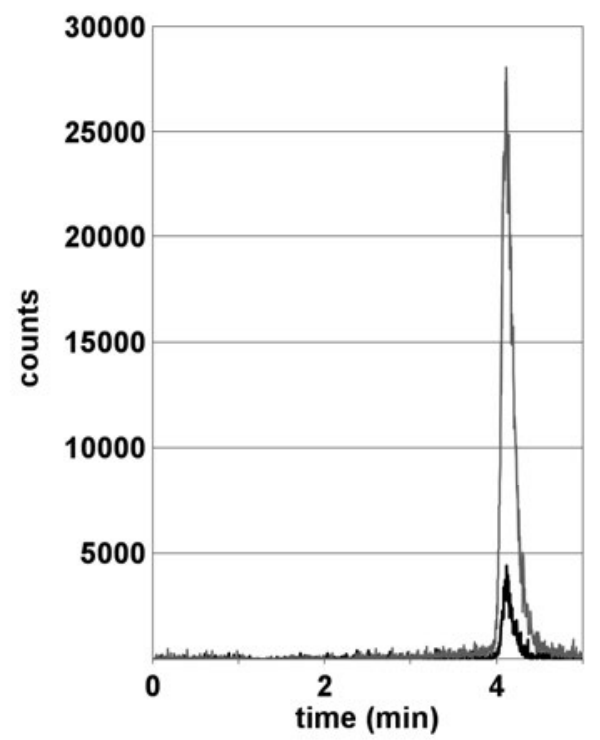

B

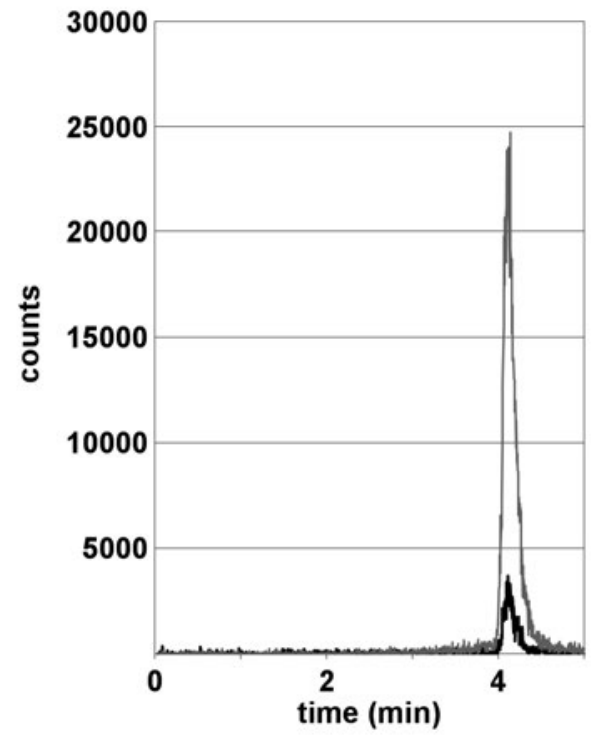

Fig. 2 Confirmation of DXR with LC-TOF MS

The extracted ion chromatograms (EICs) for doxorubicin standard and the wipe sample showing $\mathrm{m} / z$ (A) 544.18 and (B) 397.09. The gray line is for doxorubicin standard preparation (1 ppm), and the black line is for the wipe sample.

\section{Discussion}

This study revealed that there was DXR contamination on the external surfaces of drug vials produced and collected in Japan. We speculate that the external contamination originated from the manufacture or packaging process at the pharmaceutical companies because there were no breakage and leakage on the cardboard boxes and outer sides of drug vials.

In this study, we investigated the external contamination of DXR drug vials with the validated method due to obtain the reliable results. Consequently, DXR were detected on the external surfaces of DXR drug vials for the first time in Japan. On the other hand, Matsumoto et al reported that no DXR was detected on the external surfaces of vials. ${ }^{8}$ We deduce that the different results between the reports in the same country were caused by the distinction of the contamination control among pharmaceutical companies. As the reasons for that, Matsumoto et al investigated one product of one company; in contrast, we did six products of three companies. Furthermore, the product investigated by Matsumoto $e t a l$ is one of the most controlled products for the external contamination in Japan (Otsubo Y, Hirozane K, Kouda K, Uchida Y, Furukawa H, Research about Residual of Antineoplastic Drug on Vials. Department of Pharmacy, Yamaguchi University Hospital, URL: http://ds.cc.yamaguchi-u.ac. jp/ yakuzai/kouganzaifutyakutyousa.pdf).

The contamination level of each drug vial was independent of the manufacturing company and varied between two lots of the same product. Further, vial sizes from the same company did not correlate with the contamination level. We analysed a part of DXR vials distributed in Japan. Thus, it was considered that the actual contamination level of all DXR vials distributed more widely as compared with the result shown in this paper.

Hama et al monitored cyclophosphamide in the 
urine of a pharmacist who had not prepared antineoplastic drugs but had collected the drug vials." It was considered that there was the possibility of occupational exposure derived from the external surface of vials. However, the hazard of the external contamination has not known widely in Japan. One of the reasons of that was considered that there were few researches for contamination on the surfaces of drug vials. Actually, only a part of pharmaceutical companies covers a part of antineoplastic drug vials with additional packaging to prevent surface contamination, even though the Standard and Practice were published in 2007 by the International Society of Oncology Pharmacy Practitioners (ISOPP), recommends them covering. ${ }^{11)}$

In this study, we validated that the previously reported method ${ }^{8)}$ could determine contamination level on the external surfaces of DXR vials adequately. Further we revealed actual contamination level including lot-to-lot variation.

The reports about the contamination on the external surfaces of antineoplastic drug vials are insufficient in Japan, so it is important to continue to accumulate the data about the external contamination. Eventually, the attention and precautions lead to reduce the occupational exposure to antineoplastic drugs.

\section{References}

1) Falck K, Gröhn P, Sorsa M, Vainio H, Heinonen E, Holsti LR, Mutagenicity in urine of nurses handling cytostatic drugs, Lancet, 1979, 9, 1250-1251.

2) Nygren O, Gustavsson B, Ström L, Friberg A, Cisplatin contamination observed on the outside of drug vials, Ann Occup Hyg, 2002, 46, 555-557.
3) Favier B, Gilles L, Ardiet C, Latour JF, External contamination of vials containing cytotoxic agents supplied by pharmaceutical manufacturers, J Oncol Pharm Pract, 2003, 9, 15-20.

4) Mason HJ, Morton J, Garfitt SJ, Iqbal S, Jones K, Cytotoxic drug contamination on the outside of vials delivered to a hospital pharmacy, Ann Occup Hyg, 2003, 47, 681-685.

5) Connor TH, Sessink PJ, Harrison BR, Pretty JR, Peters BG, Alfaro RM, Bilos A, Beckmann G, Bing MR, Anderson LM, Dechristoforo R, Surface contamination of chemotherapy drug vials and evaluation of new vial-cleaning techniques: results of three studies, Am J Health Syst Pharm, 2005, 62, 475-484.

6) Hedmer M, Georgiadi A, Bremberg ER, Jönsson BA, Eksborg S, Surface Contamination of Cyclophosphamide Packaging and Surface Contamination with Antineoplastic Drugs in a Hospital Pharmacy in Sweden, Ann Occup Hyg, 2005, 49, 629-637.

7) Touzin K, Bussières JF, Langlois E, Lefebvre M, Gallant C, Cyclophosphamide contamination observed on the external surfaces of drug vials and the efficacy of cleaning on vial contamination, Ann Occup Hyg, 2008, 52, 1-7.

8) Matsumoto K, Naito T, Hori K, Suzuki N, Miyamoto Y, Takashina Y, Ohnishi K, Kawakami J, Surveillance of Workplace Contamination and Occupational Exposure to Antineoplastic Agents in a Hospital Setting: Establishment of a Monitoring Method Using Doxorubicin, YAKUGAKU ZASSHI, 2010, 130, 431439.

9) Hama K, Fukushima K, Hirabatake M, Hashida T, Kataoka K, Verification of surface contamination of Japanese cyclophosphamide vials and an example of exposure by handling, J Oncol Pharm Practice, 2011, 18, 201-206.

10) Horai $H$, Arita M, Kanaya S, Nihei $Y$, Ikeda T, Suwa K, Ojima Y, Tanaka K, Tanaka S, Aoshima K, Oda Y, Kakazu Y, Kusano M, Tohge T, Matsuda F, Sawada Y, Hirai MY, Nakanishi H, Ikeda K, Akimoto N, Maoka T, Takahashi H, Ara T, Sakurai N, Suzuki H, Shibata D, Neumann S, Iida T, Tanaka K, Funatsu K, Matsuura F, Soga T, Taguchi R, Saito K, Nishioka T, MassBank: a public repository for sharing mass spectral data for life sciences, J Mass Spectrom, 2010, 45, 703-714.

11) ISOPP, ISOPP Standards and Practice, J Oncol Pharm Practice, 2007, 13, Suppl, 1-81. 